\title{
PRECEDENTES JUDICIAIS E O SISTEMA JURÍDICO BRASILEIRO DE TRADIÇÃO CIVIL LAW
}

http://dx.doi.org/10.21527/2176-6622.2018.50.50-63

Recebido em: 25/5/2018

Aceito em: $13 / 9 / 2018$

Eloy Pereira Lemos Junior

Doutor em Direito pela UFMG (2007). Mestrado e especializações. Foi bolsista Capes (2005) na Universidade de Lisboa, atualmente bolsista Fundep-UFMG (desde 2013). Avaliador de cursos de Direito pelo Inep-MEC (desde 2010). Professor titular do Mestrado e da Graduação da Universidade de Itaúna (MG) e da Graduação da Unipac. Tem experiência na área de Direito, com ênfase em Direito Empresarial. Conselheiro editorial e parecerista de revistas especializadas em Direito, palestrante, orientador de trabalhos científicos, participante do Núcleo Docente Estudante (NDE) e de bancas diversas. eloy.junior@uol.com.br

Cristiano Batista

Mestrando em Proteção dos Direitos Fundamentais pela Universidade de Itaúna - UIT. Advogado. cristianobatista.cb@gmail.com

\section{RESUMO}

O Código de Processo Civil de 2015 (CPC/2015) ampliou as hipóteses de decisões vinculantes no ordenamento jurídico brasileiro, o que acirrou a controvérsia sobre a compatibilidade ou não da utilização de tal mecanismo com nosso sistema jurídico, de tradição civil law. A vinculação a determinadas decisões judiciais anteriores, estabelecida e ampliada pelo $\mathrm{CPC} / 2015$, não equivale à instituição do sistema de precedentes judiciais, instrumento integrante do common law. De qualquer forma, a vinculação a decisões judiciais anteriores busca o mesmo objetivo pretendido com a efetivação dos precedentes vinculantes, utilizado pelo common law, a partir do século 19, para a garantia da segurança jurídica. Na verdade, o que tem sido observado no mundo todo é uma aproximação entre estas duas famílias de direito, com a adoção de normas gerais e abstratas pelo common law, enquanto o civil law se utiliza, cada vez mais, do mecanismo de vinculação a precedentes. A evolução do sistema jurídico de tradição civil law, que resultou em uma maior liberdade dos magistrados na interpretação dos textos legais para criação da norma adequada ao caso concreto, acabou por gerar a necessidade de adoção de mecanismos para uma maior coerência e integridade das decisões judiciais. Procura-se, aqui, demonstrar a compatibilidade da ideia de vinculação aos precedentes com o sistema jurídico brasileiro. Foram utilizados a metodologia de pesquisa bibliográfica e o método dedutivo.

Palavras-chave: Civil Law. Aproximação com o Common Law. Decisões judiciais vinculantes. Precedentes judiciais.

\section{JUDICIAL PRECEDENTS AND THE TRADITIONAL CIVIL LAW BRAZILIAN LEGAL SYSTEM}

\section{ABSTRACT}

The Civil Process Code of 2015 extended the hypotheses of binding decisions in the Brazilian legal system, which raised the controversy about the compatibility or not of the use of such mechanism with our legal system, of civil law tradition. The linkage to certain previous judicial decisions, established and extended by $\mathrm{CPC} / 2015$, does not amount to the implementation of the system of judicial precedents, a common law instrument. In any case, the link to previous judicial decisions, seeks the same objective as the implementation of binding precedents, used by the common law, from the nineteenth century, to guarantee legal security. In fact, what has been observed throughout the world is an approximation between these two families of law, with the adoption of general and abstract norms by common law, while civil law is increasingly used of the mechanism of attachment to precedents. The evolution of the legal system of civil law tradition, which resulted in a greater freedom of magistrates in the interpretation of legal texts to create the norm appropriate to the case, eventually generated the need to adopt mechanisms for greater consistency and integrity of judicial decisions. It is sought here to demonstrate the compatibility of the idea of linking with precedents with the Brazilian legal system. Used the methodology of bibliographic research and deductive method.

Keywords: Civil Law. Approximation with Common Law. Decisions binding. Judicial Precedents,

\section{SUMÁRIO}

1 Introdução. 2 Common Law. 3 Civil Law. 4 O Termo "Precedentes" no CPC/2015. 5 Evolução do Civil Law e a Construção da Norma Pelo Judiciário. 6 Aproximação dos Sistemas Civil Law e Common Law. 7 Precedentes Vinculantes e o Direito Brasileiro de Tradição Civil Law. 8 Conclusão. 9 Referências. 


\section{INTRODUÇÃO}

O Código de Processo Civil de 2015 trouxe significativas mudanças ao ordenamento jurídico brasileiro, mas uma das alterações que tem gerado maior discussão na doutrina refere-se à adoção das decisões judiciais vinculantes.

Trata-se de uma proposta no sentido de adotar um mecanismo de vinculação a precedentes, de forma que determinadas decisões dos Tribunais Superiores e mesmo dos Tribunais de segundo grau tornem-se vinculantes para os Tribunais e juízes de primeiro grau, àqueles vinculados.

Tal alteração tem como objetivo principal a uniformização e coerência das decisões judiciais, em atenção aos princípios da isonomia e da segurança jurídica. Será, todavia, que o sistema de precedentes vinculantes pode ser instituído no Brasil, em que o Direito vigente tradicionalmente é filiado à Escola da civil law? Ou o sistema civil law é totalmente avesso à efetivação de precedentes vinculantes, sendo tal instituto compatível apenas com o sistema common law?

Essa é a questão central que procuraremos discutir no presente artigo. Não entraremos na discussão da questão da constitucionalidade ou não das alterações promovidas pelo CPC/2015, seja por questões materiais, seja por ter sido efetivada por meio de lei ordinária. Interessa-nos, antes, saber se há compatibilidade entre o sistema civil law e a ideia de precedentes vinculantes.

Quanto à metodologia, o presente artigo foi elaborado a partir de pesquisa bibliográfica, em livros, revistas, artigos, dissertações, jurisprudência e publicações disponibilizadas em sites eletrônicos, com utilização do método dedutivo.

\section{COMMON LAW}

O common law é originário de regras não escritas, a partir dos costumes locais. Foi criado a partir das decisões dos juízes ingleses e desenvolvido ao longo do tempo pela reiteração e aperfeiçoamento de tais decisões. É um direito baseado no direito costumeiro e na continuidade, razão pela qual é fruto de uma grande evolução sem interrupções (WAMBIER. 2009, p. 54).

O common law desenvolveu-se, na Inglaterra, de forma contínua e gradativa, não sendo possível visualizar a suplantação de uma ordem por outra. Nesse sentido, leiam-se as palavras de René David (2002, p. 355):

O jurista inglês - que subestima a continuidade dos direitos continentais, convencido de que a codificação provocou uma ruptura com a tradição destes direitos - gosta de valorizar a continuidade histórica do seu direito; este surge-lhe como sendo produto de uma longa evolução que não foi perturbada por nenhuma revolução; orgulha-se desta circunstância, da qual deduz, não sem razão, a prova da grande sabedoria da common law, das suas faculdades de adaptação, do seu permanente valor, e de qualidades correspondentes nos juristas e no povo inglês.

Este sistema caracteriza-se pela conjugação do direito consuetudinário com o legislado, em que a lei é apenas uma dentre as várias fontes do Direito, no entanto a norma escrita não se sobrepõe às demais fontes do Direito, como o costume, a jurisprudência e os princípios gerais.

A Revolução Gloriosa de 1688, correspondente inglês da Revolução Francesa, não tinha a pretensão de criar um novo Direito, com o fim de anular os poderes dos juízes e subjugá-los ao Legislativo. Muito pelo contrário, tal revolução pretendeu, na verdade, a afirmação do common law contra o rei, e seus princípios davam ao Judiciário condição para controlar os atos legislativos, uma vez que o Parlamento, embora supremo diante do monarca, também se encontrava submetido ao common law (MARINONI, 2009, p. 192).

No common law as normas de Direito foram sendo criadas a partir da solução de casos concretos e na utilização destas normas como orientação para solução de novos casos semelhantes. Segundo René David (2002, p. 25):

A common law foi formada pelos juízes, que tinham de resolver litígios particulares, e hoje ainda é portadora, de forma inequívoca, da marca desta origem. A regra de direito da common law, menos abstrata que a regra de direito da família romano-germânica, é uma regra que visa dar solução a um processo, e não formular uma regra geral de conduta para o futuro. 


\section{Debate}

O common law foi desenvolvido pelos Tribunais ingleses e a função da jurisprudência não foi só a de aplicar, mas também a de destacar as regras do Direito estabelecidas nas ratio decidendi dos julgados, as quais devem ser seguidas, sob pena de destruírem toda a "certeza" e comprometerem a própria existência do common law (DAVID, 2002, p. 428).

Desde sua formação, o common law mostrou sua natural inclinação em ser um sistema de case law. Embora ainda não houvesse o efeito vinculante ao precedente, os operadores de Direito inglês já ressaltavam a importância dos julgados e de que tais decisões deviam ser seguidas para se conferir a certeza e continuidade ao Direito. Isto se deve ao fato de que, desde o início, este sistema admitia a liberdade do magistrado na construção da norma a ser aplicada para a solução do caso concreto, observando-se os costumes e o direito dos antepassados.

Não é a vinculação aos precedentes (stare decisis) que caracteriza, necessariamente, o sistema common law. A expressão common law refere-se ao modelo de Direito inglês, bem caracterizado por possuir como sua principal fonte o costume. De outro lado, o stare decisis refere-se a um instrumento utilizado pelo common law para conferir certeza e segurança jurídica a este sistema.

Assinale-se, por oportuno, que, na Inglaterra, a necessidade de segurança e certeza não foi sentida sempre no mesmo grau, e só depois da primeira metade do século 19 é que se estabeleceu a regra do precedente (rule of precedent), impondo aos juízes o recurso às regras criadas pelos seus predecessores (DAVID, 2002, p. 428).

Ou seja, somente após a primeira metade do século 19 a regra do precedente se fixou rigorosamente, impondo aos juízes ingleses o recurso às regras criadas pelos seus predecessores.

Neste sistema, a ideia de vinculação do julgado precedente às demandas semelhantes surgiu nos idos do século 19, quando a Câmara dos Lordes admitiu o caráter vinculativo das suas próprias decisões nos casos Beamish versus Beamish, em 1861, referendado no caso London Street Tranways versus London County Council, este último tido como o mais célebre case. Restou decidido pelo Lord Halsbury que seria mais sensato para a sociedade que fossem estabilizados os litígios com uma solução por vezes, até mesmo, inadequada, do que eternizar as incertezas e inseguranças (LEITE, 2017, p. 4).

Observe-se que, nesta decisão, ficou estabelecida a vinculação de todos os órgãos inferiores, bem como da própria Casa dos Lordes, que também ficava vinculada as suas decisões anteriores. Anos mais tarde, decidiu-se que a Casa dos Lordes poderia, em um momento futuro, rever seu próprio precedente, desde que demonstrasse, fundamentadamente, as razões, sejam jurídicas, sociais, econômicas, etc., pelas quais se justificaria tal alteração.

Assim, o efeito vinculante das decisões já proferidas encontra-se condicionado à posição hierárquica do Tribunal que as profere. Nesse sentido, as decisões vinculam a própria Corte que a profere (eficácia interna), bem como todos os órgãos inferiores (eficácia externa).

É conveniente sublinhar que os únicos precedentes obrigatórios são constituídos pelas decisões emanadas dos Tribunais superiores (Supreme Court of Judicature e Câmara dos Lordes), de forma que as decisões emanadas de outros Tribunais podem ter um valor persuasivo, mas não vinculativo (DAVID, 2002, p. 429).

Pela técnica do precedente obrigatório, no sistema do common law é necessário que a Corte ou o juiz, ao decidir o caso concreto, fundamente sua decisão em uma decisão anterior ou em uma jurisprudência de Tribunal superior.

Marinoni também afirma que a doutrina do stare decisis não se confunde com o próprio sistema do common law. O common law existiu por vários séculos antes de surgir o stare decisis, ou seja, a vinculação dos precedentes. O stare decisis é apenas um elemento presente dentro do modelo jurídico do common law (MARINONI, 2010, p. 33). Ou seja, no common law os juízes sempre tiveram de observar o Direito costumeiro, mas apenas de uns tempos para cá é que tiveram qde respeitar, obrigatoriamente, os precedentes judiciais.

Deve-se registrar também que não é a existência ou não de leis ou de codificação que distingue o civil law do common law. O common law também tem intensa produção legislativa, entretanto, a diferença entre os dois sistemas está na importância que se dá para as leis e códigos em cada um deles (MARINONI, 2009, p. 46-47). 
Apesar de também existirem leis, nesse sistema, a solução dos casos concretos é criada a partir das decisões judiciais, os chamados precedentes, que são decisões judiciais anteriores utilizadas para a solução de casos idênticos ou semelhantes. O Direito interpretado e declarado judicialmente tem primazia sobre o Direito legislado.

Registre-se que no common law a vinculação aos precedentes (stare decisis) foi assimilada sem sobressaltos, de forma natural, pois são as próprias decisões judiciais anteriores que criam, a partir dos costumes e das circunstâncias do caso concreto, as normas jurídicas a serem utilizadas no julgamento de casos análogos posteriores.

No common law os juízes sempre tiveram liberdade para interpretar e criar a norma aplicável ao caso concreto, porém deviam observar os costumes e, posteriormente, os precedentes judiciais, ou seja, os julgados anteriores em que foram decididas as mesmas questões de Direito.

Nesse sistema, procurou-se garantir o princípio da igualdade e da segurança jurídica, não mediante a observância estrita da norma legal abstrata consignada em lei, posto que esta não é a principal fonte de Direito, mas pelo respeito às decisões judiciais anteriores, por meio da vinculação obrigatória aos precedentes (stare decisis).

No common law, a segurança não foi buscada na lei, e sim nos precedentes, que se mostravam como instrumento hábil a garantir certeza e previsibilidade na aplicação do Direito (MARINONI, 2009, p. 199).

\section{CIVIL LAW}

O sistema romano-germânico, também denominado civil law, tem sua origem na Europa continental, podendo-se afirmar que, do ponto de vista científico, surgiu no século 13. Até esta época existem, sem dúvida alguma, elementos com a ajuda dos quais o sistema será constituído, mas parece prematuro falar de sistema, e talvez mesmo de Direito.

O civil law pode ser dividido em períodos. Um primeiro período começa, no século 13, com o renascimento dos estudos de Direito Romano nas universidades. [...] Durante cinco séculos o sistema vai ser dominado pela doutrina, sob a influência principal da qual a própria prática do Direito evoluirá nos diferentes Estados. A doutrina preparará, com a Escola do Direito Natural, o despertar do período seguinte, aquele em que ainda atualmente nos encontramos - período no qual o sistema será dominado pela legislação (DAVID, 2002, p. 35).

O desenvolvimento do civil law ocorreu dentro das universidades, onde não havia preocupação com a prática do Direito, mas principalmente com um método capaz de compreender as regras materiais mais justas, mais conformes à moral. As universidades não se dedicavam a estudar os costumes ou o Direito local, pois não os consideravam verdadeiramente Direito. Devido à diversidade e à barbárie dos costumes e do Direito local, estes foram desprezados pelas universidades, que passaram a se dedicar ao Direito Romano.

Nesse sentido, René David (2002, p. 52) afirma que:

O renascimento dos estudos de Direito Romano é o principal fenômeno que marca o nascimento da família de Direito Romano-Germânica. Os países que pertencem a essa família são, na História, aqueles em que os juristas e práticos do Direito, quer tenham ou não adquirido a sua formação nas universidades, utilizam classificações, conceitos e modos de argumentação dos romanistas.

Com o tempo, o Direito ensinado nas universidades afasta-se do Direito Justiniano, adaptando-se às necessidades da sociedade moderna, para se tornar um Direito sistemático, fundado sobre a razão, tendo por isto vocação para ser aplicado de modo universal (DAVID, 2002, p. 46).

Nos séculos 17 e 18, a escola do Direito natural renova completamente a ciência do Direito, inovando seus métodos, levando a uma tendência axiomática e dando primazia à legislação como fonte do Direito.

Pode-se afirmar que a Revolução Francesa foi o grande marco histórico para a consolidação do sistema jurídico denominado civil law, que conforme descrito anteriormente, já vinha se desenvolvendo na Europa continental. Na França, com a revolução de 1789, ocorreu a queda da monarquia absolutista e uma nova classe, a burguesia, ascende ao poder. 
Com a tomada do poder, a burguesia revolucionária promoveu uma verdadeira ruptura com o modelo de Estado absolutista. Nesse contexto, era necessário criar um novo sistema jurídico capaz de afastar as antigas concepções monárquicas e, ao mesmo tempo, limitar a atuação dos magistrados, ainda aliados ao antigo regime.

Em relação a eles, que eram da classe aristocrática, foi-lhes atribuída a função de dizer o Direito, em completa subordinação ao poder Legislativo, em razão do receio de que pudessem frustrar os fins da revolução, caso permanecessem com o poder e a liberdade de aplicar livremente o Direito. Para atender à necessidade de controlar a atuação judicial estabeleceu-se a primazia da lei, ficando o trabalho dos juízes limitado à aplicação literal do texto legal.

Corroborando tal assertiva, Marinoni (2009, p. 46) afirma que:

Para a Revolução Francesa, a lei seria indispensável para a realização da liberdade e da igualdade. Por este motivo, entendeu-se que a certeza jurídica seria indispensável diante das decisões judiciais, uma vez que, caso os juízes pudessem produzir decisões destoantes da lei, os propósitos revolucionários estariam perdidos ou seriam inalcançáveis. A certeza do Direito estaria na impossibilidade de o juiz interpretar a lei, ou melhor dizendo, na própria lei. Lembre-se que, com a Revolução Francesa, o poder foi transferido ao Parlamento, que não podia confiar no Judiciário.

Com a Revolução Francesa de 1789, portanto, houve uma clara ruptura da ordem política e jurídica. A luta contra o absolutismo significou a pretensão de substituir o rei por outro poder absoluto, a Assembleia Soberana. O Parlamento avocou para si a competência exclusiva de criar o Direito, de forma que a atividade dos juízes deveria se restringir à mera declaração da lei.

$\mathrm{Na}$ França revolucionária proibiu-se o juiz de interpretar a norma; imaginando-se que uma legislação clara e completa possibilitaria a ele simplesmente aplicar a lei, e, desta maneira, solucionar os casos litigiosos sem a necessidade de estender ou limitar o alcance da lei.

Neste sistema, a lei passa a ser a fonte primária do Direito e deve ser aplicada em sua literalidade. O juiz deve restringir sua decisão àquilo que se extrai do texto legal. Os juízes passam, assim, a meros espectadores do Direito, exercendo apenas a função de declarar a vontade da lei, na famosa expressão de que o juiz é a "boca da lei".

No Estado liberal francês, mesmo em caso de omissão que impusesse interpretação, os juízes deveriam recorrer ao Legislativo, solicitando uma "interpretação autorizada" (MERRYMAN apud ATAÍDE JR., 2013, p. 564), elaborada por meio de comissões, que posteriormente deram origem às Cortes de cassação, cuja função era a de cassar qualquer decisão judicial contrária aos propósitos do legislador. Os juízes, portanto, estavam totalmente limitados a afirmar o que já fora assegurado pelo Legislativo, sem qualquer possibilidade de interpretação ou criação.

O positivismo decorrente do período pós-revolução francesa deu ensejo à instituição do império da lei, como forma de se atribuir segurança jurídica, uma vez que a vinculação ao texto legal traria previsibilidade nas decisões judiciais. O Legislativo, como representante dos anseios do povo, deveria elaborar leis claras e que abrangessem todas as searas possíveis e imagináveis do comportamento humano, de onde a norma seria extraída, sem qualquer margem interpretativa ou criativa.

\section{O TERMO “PRECEDENTES” NO CPC/2015}

Precedentes, na perspectiva do common law, são decisões anteriores que servem como ponto de partida ou modelo para a decisão de novos casos semelhantes. São decisões em que a mesma questão jurídica, sobre a qual há que se decidir novamente, já foi resolvida por um Tribunal, noutro caso.

Em seu sentido tradicional, uma decisão judicial não nasce como "precedente", mas ela pode vir a se tornar um, em momento posterior, quando vier a ser utilizada como subsídio ou modelo para decisão de caso semelhante. Nas palavras de Eduardo Talamini (2016, p. 1):

Até há pouco, a expressão "precedente judicial" tinha um sentido distinto daquele em que agora ele tem sido empregado. [...] Falava-se em "precedente" para se referir a um pronunciamento judicial proferido no passado e identificado, em um momento posterior, como sendo um subsídio relevante ou decisivo para a resolução de 
novos casos, em que a mesma ou análoga questão se ponha. [...] Nesse sentido tradicional, o precedente é identificado como tal não no momento em que é emitido, mas depois, quando invocado, interpretado e utilizado como subsídio ou baliza para uma nova decisão.

No Brasil, recentemente, passou-se a utilizar o termo "precedente" para designar alguns pronunciamentos judiciais que, no momento em que são emitidos, já nascem com a função de servir de parâmetro, com maior ou menor grau de vinculação, para decisões judiciais futuras de casos em que se discuta a mesma questão jurídica. Nesse sentido, "precedentes" são os julgados que, desde a sua prolação, a lei determina que tenham força vinculante obrigatória.

No common law, diversamente, qualquer decisão judicial, bem fundamentada e coerente com os princípios e valores daquele sistema jurídico, pode vir a ser um precedente, desde que utilizada como parâmetro para decisão de casos futuros semelhantes.

É por essa diferenciação que alguns autores têm se manifestado no sentido de que o $C P C / 2015$, em seu artigo 927, adotou um sistema de decisões vinculantes, bem diferente de um sistema de precedentes judiciais vinculantes. Nesse sentido, Flávio Quinaud Pedron e José Emílio Medauar Ommati (2017/2018, p. 666) afirmam que:

Sendo assim, no caso do Código de Processo Civil de 2015, o que veremos é a instituição, no art. 927, de um sistema de decisões vinculantes, o que já é bem diferente de precedentes judiciais (BRASIL, 2015). A vinculatividade futura de tais provimentos não decorre de uma apropriação crítica das gerações futuras, como ocorre com as decisões judiciais na Inglaterra e nos EUA, mas sim do fato de obedecerem a um procedimento que ao final dota o provimento de tal natureza vinculante.

Feito o registro da divergência na compreensão do termo "precedente" no common law e aquele utilizado no $\mathrm{CPC} / 2015$, passemos à análise do princípio da segurança jurídica, do processo de aproximação entre estas duas famílias jurídicas e, por fim, da compatibilidade dos precedentes, no sentido em que é empregado no sistema anglo-saxônico, ao sistema jurídico brasileiro, filiado ao civil law.

\section{EVOLUÇÃO DO CIVIL LAW E A CONSTRUÇÃO DA NORMA PELO JUDICIÁRIO}

No Direito de tradição civil law procurou-se garantir a prevalência dos princípios da igualdade e da segurança jurídica, a partir de uma rigorosa separação de poderes e na aplicação estrita da lei, com grandes limitações na margem de interpretação dos juízes, que estavam impedidos de criar norma. A segurança jurídica estaria necessariamente atrelada à observância pura e simples da lei.

De outro lado, como vimos, o sistema common law, originário da Inglaterra, para garantir a segurança jurídica deu preferência a um sistema em que o direito dos antepassados devia ser mantido e, posteriormente, utilizou-se do recurso de precedentes judiciais vinculantes, em que os magistrados deviam observância obrigatória às decisões judiciais anteriores de casos semelhantes.

Veja-se que em ambos os sistemas, seja no common law, seja no civil law, o princípio da segurança jurídica é um valor fundamental. Nesse sentido, podemos citar:

A segurança jurídica é valor caro a qualquer sistema jurídico e, obviamente, interessa aos sistemas das duas tradições jurídicas, sendo que o civil law, historicamente, perseguiu-a através do texto da lei e, o common law, mediante o precedente vinculante (stare decisis) (ATAÍDE JR., 2013, p. 575).

No civil law, originário da Europa continental, procurou-se garantir a segurança jurídica por meio da valorização da lei escrita e da codificação, buscando-se limitar ou suprimir a liberdade de interpretação.

Ocorre que a vida social é dinâmica. Em que pese a lei ainda ser considerada fonte primária do Direito, não é possível conceber, no momento atual, um Direito exclusivamente legalista. Não se pode admitir um ordenamento dissociado de qualquer interpretação jurisdicional, seja porque a sociedade passa por constantes modificações (culturais, sociais, políticas, econômicas, etc.), que não são acompanhadas pelo legislador, seja porque este nunca será capaz de prever solução para todas as situações concretas e futuras submetidas à apreciação judicial. 
Além disso, o desenvolvimento de uma sociedade de consumo, globalizada, gerou também uma infinidade de conflitos de massa. Todas estas transformações acarretaram também uma maior complexidade nas demandas que aportam ao Judiciário, impondo uma maior atenção e capacidade do juiz na solução dos casos concretos.

A consequência é que a lei escrita não é mais (se é que algum dia foi) capaz de prever solução adequada para todas as questões apresentadas em juízo. O legislador parte, então, para a confecção de um texto legal mais maleável, mais aberto e sujeito a interpretações mais fluidas por parte do Judiciário.

Passa-se, na elaboração das leis, à utilização crescente de cláusulas gerais e conceitos jurídicos indeterminados. ${ }^{1} \mathrm{O}$ método subsuntivo ainda pode ser adequado para o trato de algumas normas de tipicidade rígida, mas não se presta à interpretação de cláusulas gerais e conceitos jurídicos indeterminados. A concreção, que impõe uma maior liberdade ao julgador, é o método próprio para a aplicação das normas de textura aberta.

A concreção é um método hermenêutico que proporciona aos juízes uma possibilidade maior de responder, de forma efetiva e adequada, às variadas demandas sociais, mas, ao mesmo tempo, expande a liberdade do julgador na criação da norma do caso concreto, a partir do texto legal.

Com efeito, o silogismo subsuntivo, próprio da Modernidade e do Positivismo jurídico do século 19, quando vigorava o dogma da estrita aplicação da lei, é impróprio para lidar com normas de textura aberta, com cláusulas gerais e conceitos indeterminados, que exigem uma construção de sentido diante do caso concreto (ÁVILA, 1997, p. 423).

Ademais, nos últimos tempos tem ganhado força um processo de constitucionalização do Direito, no qual a legislação infraconstitucional deve ser interpretada à luz dos comandos constitucionais, de seus princípios e valores, o que proporciona uma liberdade ainda maior aos julgadores na interpretação da norma a ser aplicada ao caso concreto.

Essa constitucionalização do Direito provocou profundas transformações no civil law, aproximando-o bastante do common law. Com efeito, se o juiz não aplica a lei por reputá-la inconstitucional, interpreta-a conforme a Constituição ou supre uma omissão, pode-se afirmar que sua atividade se limita a declarar a vontade da lei?

É que, a partir do momento em que a lei perdeu a supremacia, submetendo-se à Constituição, a atividade do juiz das famílias romano-germânicas tornou-se bem parecida à dos seus colegas ingleses e norte-americanos, que controlam a lei a partir do common law e da Constituição, respectivamente. Isso torna-se ainda mais evidente com a adoção, pelos países do civil law, do sistema de controle difuso de constitucionalidade, que concede aos magistrados o poder de afastar o comando legal sob alegação de violação a preceitos constitucionais.

A contemporaneidade, por sua própria complexidade, exige uma maior atividade criativa dos juízes de tradição civil law quando da aplicação do Direito, que mesmo permanecendo em grande medida codificado, possui notórias aberturas interpretativas.

Os próprios defensores do positivismo abandonaram o mito da lei, tal como se apresentava no século 19. Nos dias atuais reconhece-se o papel criativo do juiz; já ninguém acredita que a lei seja a única fonte do Direito e que uma operação puramente lógica de interpretação possa, em todos os casos, conduzir à descoberta da solução de direito adequada (DAVID, 2002, p. 113).

Nos dias de hoje é sabido que as normas jurídicas não são os textos de lei. Na verdade, as normas são os sentidos construídos a partir da conformação constitucional e da interpretação sistemática dos textos legais. Os dispositivos de lei constituem-se no objeto da atividade hermenêutica e as normas são o resultado desse processo de interpretação.

\footnotetext{
${ }^{1}$ Como exemplos, podemos citar: Constituição Federal que fala da função social da propriedade (art. 50, XXIII, CF); devido processo legal (art. 5ㅇ, LIV, CF) e razoável duração do processo (art. 5ㅇ, LXXVIII, CF); o Código Civil ao falar: da boa-fé contratual (art. 422, CC); função social do contrato (art. 421, CC); interpretação mais favorável ao aderente (art. 423, CC).
} 
A liberdade de interpretação, entretanto, exigida pela atual conjuntura, leva a decisões divergentes para casos semelhantes, conduzindo ao descrédito do Judiciário, à falta de uniformidade das decisões judiciais e, por fim, à violação flagrante do princípio da segurança jurídica.

A evolução do civil law, que inicialmente negava aos juízes liberdade de interpretação, acabou por conceder ao juiz o poder de interpretar, completar e negar o Direito produzido pelo Legislativo e até mesmo de criá-lo, com base em princípios constitucionais, na tutela de um direito fundamental, quando haja omissão do legislador.

Discorrendo sobre a criatividade judicial, Mauro Cappelletti (1993, p. 123-124) afirma que é evidente o aumento da criatividade jurídica nos países de civil law da mesma forma que ocorre no common law, com as diferenças mostrando-se cada vez mais atenuadas entre ambos, resultando no que Cappelletti denomina de "convergência evolutiva".

Mais adiante, o mesmo autor conclui no sentido de que, atualmente, é dominante, nas duas grandes famílias do Direito, o entendimento segundo o qual a atividade do juiz é interpretativa e criativa, pois a interpretação sempre implica um certo grau de discricionariedade e escolha e, portanto, de criatividade (CAPPELLETTI, 1993, p. 128-129).

Nesse cenário, pode-se perceber que, diante da multiplicidade de interpretações possíveis e admissíveis, não há como se obter a certeza jurídica, simplesmente, no texto da lei.

A ordem jurídica, por óbvio, não é formada apenas pelas leis, mas é constituída também pelas decisões judiciais, que dão concretude às normas extraídas do texto legal para a solução das controvérsias. Não obstante, as decisões judiciais devem se manter uniformes e garantir que julgamentos de casos idênticos tenham a mesma solução jurídica, dando mostras de coerência e de atenção ao princípio da segurança jurídica.

O sistema jurídico brasileiro necessita, urgentemente, de mecanismos que garantam essa uniformização e convergência da jurisprudência de nossos tribunais. Em resposta a esta necessidade, o CPC/2015 ampliou as hipóteses de julgados que apresentam força vinculante obrigatória. Afinal, os precedentes vinculantes são ou não compatíveis com o nosso sistema jurídico, filiado à família civil law?

\section{APROXIMAÇÃO DOS SISTEMAS CIVIL LAW E COMMON LAW}

A diferença entre as duas grandes famílias de sistemas jurídicos reside basicamente no fato de que, no âmbito da família romano-germânica, busca-se a solução do caso concreto partindo-se da lei, de uma regra geral e abstrata, enquanto no Direito anglo-saxônico pretende-se o mesmo resultado, só que levando em consideração, prioritariamente, as decisões judiciárias de casos análogos anteriores.

Nesse viés, nos últimos tempos diversos doutrinadores têm chamado a atenção para um processo de aproximação entre as famílias civil law e common law.

Os países filiados ao Direito da família common law legislam, cada vez mais, por meio de leis, e, em contrapartida, os Estados de tradição civil law têm introduzido em seu ordenamento jurídico a força vinculante dos precedentes judiciais.

É importante destacar que com o surgimento do Constitucionalismo, os países de civil law passaram a atribuir mais importância à jurisprudência como fonte do Direito, ao mesmo tempo em que os países de common law passaram a dar maior relevo à lei.

Atualmente, portanto, enfraquece a ideia de dicotomia entre as famílias de Direito civil law e common law, pois o Direito legislado cresce no common law, ao passo que a jurisprudência se destaca nos países que adotaram o civil law.

No mesmo sentido, Luiz Guilherme Marinoni (2010, p. 4) assevera que:

Não há dúvida de que o papel do atual juiz do civil law e, principalmente, o do juiz brasileiro, a quem é deferido o dever-poder de controlar a constitucionalidade da lei no caso concreto, muito se aproxima da função exercida pelo juiz do common law, especialmente a da realizada pelo juiz americano.

Verifica-se que há uma troca mútua de informações, experiências e mecanismos entre estas duas famílias de sistemas jurídicos. Conforme ensina Marco Antônio da Costa Sabino (2010, p. 52): 


\section{Debate}

A tendência moderna do direito judiciário aponta para uma aproximação entre eles, justamente para que no âmbito do common law o direito escrito seja mais celebrado, enquanto que, no campo do civil law, os precedentes judiciais ocupem lugar de maior destaque.

Parece ser esta uma tendência inevitável, na medida em que ambos os sistemas jurídicos buscam a mesma finalidade, qual seja, gerar previsibilidade, respeitar a isonomia e garantir segurança jurídica, pois, enquanto o common law necessita da adoção de normas gerais e abstratas visando a dar maior sistematicidade ao Direito, o civil law carece do precedente vinculante, a fim de, por meio da certeza jurídica proporcionada pela jurisprudência, melhor delimitar a possibilidade de múltiplas pautas de conduta de uma lei (ATAÍDE, 2013, p. 601).

\section{PRECEDENTES VINCULANTES E O DIREITO BRASILEIRO DE TRADIÇÃO CIVIL LAW}

Como visto anteriormente, os precedentes vinculantes (stare decisis) não são elementos intrínsecos do sistema common law, que já existia muito antes da instituição desse mecanismo de vinculação obrigatória. $O$ stare decisis foi o mecanismo escolhido, no Direito anglo-saxônico, para limitar a ampla liberdade outorgada aos juízes, naquele sistema, para interpretar e criar a norma do caso concreto, como forma de estabilização da jurisprudência e garantia da segurança jurídica.

Originariamente, no civil law, não possuíam os juízes qualquer liberdade no trabalho de interpretação da norma, a partir do texto legal. A tarefa do juiz limitava-se a dizer o Direito contido no texto legal, aplicando de forma estrita aquilo que fora estabelecido pelo legislador.

A evolução do civil law, com a constitucionalização do Direito e uma maior utilização de conceitos abertos e cláusulas gerais na elaboração dos textos legais, bem como as rápidas transformações da sociedade moderna e seu crescente grau de complexidade, exigiram da atividade judicial uma maior criatividade no seu trabalho de solução adequada das controvérsias que, cada vez mais, em número e complexidade crescentes, aportam ao Judiciário.

Em consequência dessa maior liberdade de interpretação, houve uma dispersão enorme dos julgados, havendo decisões divergentes e até contraditórias, para casos semelhantes ou idênticos, sem a existência de qualquer circunstância relevante que as justifique. O resultado de tudo isso é um Judiciário desacreditado, uma falta de confiança na Justiça e a constante violação ao princípio da segurança jurídica.

É necessário e urgente, portanto, nos ordenamentos jurídicos filiados ao civil law e, em especial, no Brasil, o estabelecimento de mecanismos eficazes de uniformização da jurisprudência e de garantia da isonomia nas decisões judiciais, ou seja, garantir que casos semelhantes tenham solução semelhante.

A opção do CPC/2015 pela instituição do mecanismo de vinculação obrigatória a determinadas decisões judiciais tem sido muito criticada pela doutrina, chegando-se a afirmar a sua inconstitucionalidade, seja por razões materiais e/ou formais.

Sem entrar na discussão sobre a constitucionalidade ou não dos dispositivos legais do CPC/2015 que tratam do tema, procuraremos demonstrar que o civil law, e em especial o ordenamento jurídico brasileiro, é totalmente compatível com a técnica de vinculação aos precedentes.

Segundo Marinoni (2009, p. 179), são três as razões apontadas pela doutrina para justificar a incompatibilidade da adoção do stare decisis nos países do civil law: a) o common law não existe sem o stare decisis; b) o juiz do common law cria o Direito, desempenhando função diversa do juiz do civil law; c) o stare decisis é incompatível com o civil law.

O mesmo autor afasta tais argumentos afirmando, primeiramente, como já demonstrado antes, que não há como se confundir o common law com o mecanismo de stare decisis. O common law teve origem nos séculos 12 e 13, com a observância dos costumes, enquanto a vinculação aos precedentes foi estabelecida, de forma obrigatória, apenas na segunda metade do século 19.

Do mesmo modo, a atividade criativa do juiz, ao decidir os casos concretos, não está relacionada à adoção ou não do stare decisis. Atualmente, mesmo nos países de tradição romano-germânica, não se nega a atividade criativa do juiz, tendo em vista que o enunciado normativo não é simplesmente extraído do texto legal, mas construído no momento de decidir o caso concreto, com base nos princípios e valores constitucionais, estabelecendo-se o sentido exato dos conceitos jurídicos indeterminados e das cláusulas gerais. 
Também não há fundamento na alegação de que o stare decisis seja incompatível com os sistemas em que a lei seja a fonte primária do Direito. Veja-se que há países filiados ao common law, como os Estados Unidos, em que a produção legislativa é tão intensa como em países de tradição civil law. Da mesma forma, a Inglaterra tem produzido leis, a exemplo do Código de Processo Civil, sem que isso tenha inviabilizado o sistema de vinculação aos precedentes judiciais, nos referidos países.

De outro lado, os países de tradição civil law há algum tempo já vêm adotando mecanismos de vinculação aos precedentes, notadamente em relação às decisões de suas Cortes Constitucionais ou Tribunais superiores, a exemplo do Brasil.

Nesse sentido, é importante registrar que nos países de civil law, a adoção do sistema de controle difuso provocou sérios e graves inconvenientes, na medida em que proporcionou o surgimento de decisões conflitantes a respeito da constitucionalidade de uma mesma lei. É que se qualquer magistrado tem o poder-dever de apreciar a constitucionalidade das leis, pode muito bem ocorrer que alguns juízes declarem a inconstitucionalidade de determinado dispositivo legal e deixem de aplicá-lo e, outros, pelo contrário, reputem-no constitucional e continuem a aplicá-lo. Pode ocorrer, ainda, que mesmo a mais Alta Corte tendo decidido a respeito da (in)constitucionalidade de determinada lei, os juízes de Primeira Instância continuem a julgar em sentido contrário, uma vez que não estão vinculados ao precedente (CAPPELLETTI, 1992, p. 77-78).

Corroborando tal entendimento, em conferência proferida no Congresso de Direito Processual, realizado pelo Instituto dos Advogados do Paraná, em 2010, Luiz Guilherme Marinoni chega a afirmar:

Mas é exatamente aí que aparece o brutal problema do nosso tempo. O sistema brasileiro - que adota o controle difuso de constitucionalidade - não se deu conta de que esta forma de poder judicial coloca em risco a coerência da ordem jurídica, a segurança e a igualdade, valores fundamentais em qualquer Estado de Direito. ${ }^{2}$

Segundo Cappelletti (1992, p. 69), o sistema de controle difuso norte-americano foi importado, de forma um tanto quanto ingênua, por países da tradição de civil law, que não atentaram para o fato de que tal modelo não tinha como prosperar sem a doutrina do stare decisis.

Não é à toa que alguns dos países do civil law que adotaram o sistema de controle difuso, a fim de evitar decisões conflitantes, passaram a atribuir eficácia vinculante aos precedentes do órgão encarregado de dar a última palavra em matéria constitucional. A título de exemplo, cita-se a Suíça (CAPPELLETTI, 1992, p. 79).

Ainda de acordo com o ensinamento de Cappelletti, a vinculação obrigatória aos precedentes judiciais não é apenas e tão somente compatível, mas até mesmo necessária ao ordenamento jurídico de países de tradição romano-germânica que tenham adotado o controle de constitucionalidade difuso, com o objetivo de dar coerência e garantir a isonomia e a segurança jurídica.

Nesse raciocínio, a adoção do stare decisis torna-se decorrência lógica do próprio sistema civil law, dentro do modelo instituído no Brasil, como procuraremos demonstrar a seguir.

Imagine-se que o STF, em controle concreto de constitucionalidade, tenha declarado a inconstitucionalidade de uma determinada lei federal. Tal decisão tem efeitos apenas inter partes, sem qualquer efeito vinculante.

Nessa situação, entretanto, não se pode conceber que um juiz de primeiro grau continue a aplicar lei federal declarada inconstitucional pelo STF; ou, de outro lado, que Tribunais de segundo grau continuem a deixar de aplicar lei federal declarada constitucional pelo STF, em ação declaratória de constitucionalidade, sob alegação de que no seu entendimento referida norma é inconstitucional. Tal situação é inaceitável do ponto de vista da racionalidade e da lógica de nosso sistema de Direito, em vista da hierarquia de nosso poder Judiciário.

Tais situações são completamente absurdas, pois permitem que uma mesma lei seja considerada constitucional para uns e inconstitucional para outros. Ou seja, não há racionalidade nenhuma num sistema de controle de constitucionalidade, em que as decisões do órgão máximo do Judiciário, intérprete último da Constituição, não têm efeito vinculante.

\footnotetext{
${ }^{2}$ Conferência proferida no Congresso de Direito Processual, realizado em 2010, no Paraná. Disponível em: <http: //www.marinoni.adv.br/ wp-content/uploads/2016/08/Confer\%C3\%Aancia_IAP2.pdf>. Acesso em: 4 jan. 2018.
} 
No Brasil, com o objetivo de evitar este óbvio inconveniente, criou-se o instituto original da Resolução Suspensiva do Senado, introduzido pela Constituição de 1934 e ainda presente no artigo 52, inciso X, da CRFB/1988. Mediante tal resolução, o Senado pode suspender a execução do ato declarado inconstitucional pelo Supremo, como forma de conferir eficácia erga omnes às decisões definitivas sobre inconstitucionalidade, em sede de recursos extraordinários.

Mais recentemente, o próprio STF tem concedido efeito vinculante e erga omnes às suas decisões, ${ }^{3}$ mesmo que tomadas em sede de controle difuso, o que tem sido chamado de abstrativização do controle difuso, dando-se nova interpretação ao disposto no artigo 52, inciso X, da CRFB/1988, sob o fundamento de mutação constitucional. Nesse caso, caberia ao STF apenas comunicar sua decisão ao Senado Federal, com o objetivo de que a referida Casa Legislativa dê publicidade daquilo que foi decidido.

Independentemente de qualquer disposição legal que estabeleça tal comando, por racionalidade e lógica do próprio sistema, a decisão final do STF sobre a constitucionalidade ou não de determinada lei deveria ter efeitos vinculantes obrigatórios sobre todas as decisões de juízes, Tribunais superiores e Tribunais de segunda instância, posto que todos estão submetidos às decisões daquele Tribunal.

É exigência óbvia de um ordenamento jurídico racional que casos semelhantes sejam tratados e julgados de forma semelhante, exceto se forem detectadas circunstâncias específicas que demandem decisão diversa. Desse modo, a ideia de vinculação aos precedentes, longe de ser uma característica única e exclusiva do Direito filiado ao common law, é decorrência inafastável de todo ordenamento jurídico racional, que busque a observância aos princípios da isonomia e da segurança jurídica.

Nesse sentido, importante destacar as palavras de Taruffo (1996, p. 795):

Va anzitutto sottolineata la grande importanza che l'impiego del precedente e della giurisprudenza riveste nella vita de il diritto di tutti gli ordinamenti moderni. Ricerche svolte in vari sistemi giuridici hanno dimostrato che il riferimento al precedente non è più da tempo uma caratteristica peculiare degli ordinamenti di common law, essendo ormai presente in quis tutti i sistemi, anche di civil law. ${ }^{4}$

De modo semelhante, pode-se defender a vinculação de decisões do STJ, relativamente à interpretação da legislação infraconstitucional. É inaceitável que os Tribunais de segunda instância insistam em dar interpretação própria à legislação infraconstitucional, quando o STJ já tenha firmado entendimento em sentido contrário ou divergente, pois a este cabe a tarefa de estabelecer, em última instância, o sentido da norma infraconstitucional.

No Brasil, porém, nunca se deu a devida atenção a tal exigência lógica do sistema jurídico. Em uma supervalorização do princípio da legalidade, contido no artigo 5으, II, da CRFB/88, repetido em normas infraconstitucionais, aqui só tem validade jurídica o que está estabelecido, expressamente, em lei.

Mesmo tratando-se de decisões do STF em controle concentrado, houve necessidade de previsão legal expressa, para que estas passassem a ter efeito vinculante e erga omnes, de forma incontroversa. Exemplo disso é a alteração da redação do artigo 102, I, a, da CRFB/88, que criou a Ação Declaratória de Constitucionalidade (ADC), tendo sido consignado, expressamente, no $\$ 2$ desse mesmo dispositivo constitucional, que a decisão proferida em tal ação produziria eficácia contra todos e efeito vinculante, relativamente aos demais órgãos do poder Judiciário e ao poder Executivo. Nessa época, não havia ainda, para a Ação Direta de Inconstitucionalidade (ADI), norma expressa estabelecendo o seu efeito vinculante.

Assim, quando da publicação da Lei 9.868/1999, que dispõe sobre o processo e julgamento da ADI e ADC, o legislador estabeleceu, no artigo 28 , §2으, que as decisões prolatadas nestas ações têm eficácia contra todos e efeito vinculante em relação aos órgãos do poder Judiciário e à administração pública federal, estadual e municipal.

\footnotetext{
${ }^{3}$ Nesse sentido: STF. Plenário. ADI 3406/RJ e ADI 3470/RJ, Rel. Min. Rosa Weber, julgados em 29/11/2017 (Informativo 886).

${ }^{4}$ Em primeiro lugar, é importante sublinhar a grande importância que o uso do precedente e da jurisprudência tem na vida do Direito de todos os sistemas modernos. Pesquisas realizadas em vários sistemas legais mostraram que a referência aos precedentes deixou de ser, há muito tempo, uma característica peculiar dos sistemas de common law, uma vez que estão presentes em todos os sistemas, mesmo de tradição civil law.
} 
A rigor, tais dispositivos seriam desnecessários, pois tais regras decorrem da própria lógica e racionalidade do sistema. O mesmo ocorre com as decisões do STF, em controle concentrado, que estabeleçam a interpretação conforme a Constituição, a declaração parcial de inconstitucionalidade sem redução de texto ou as súmulas que, necessariamente, também têm a mesma eficácia erga omnes e efeito vinculante. Nessa perspectiva, fica sem sentido falar-se em "súmula vinculante", dado que este é, ou, pelo menos deveria ser, um efeito lógico, inerente a todas as súmulas do STF.

Resta patente que inexiste incompatibilidade entre o civil law e o stare decisis, muito pelo contrário, países de civil law têm caminhado rumo ao precedente vinculante, visando a assegurar maior previsibilidade às decisões judiciais (ATAÍDE, 2013, p. 577).

O que ocorreu, no Brasil, ao longo dos anos, é que não foi dada a devida atenção ao grave problema da dispersão da jurisprudência e muito pouco têm sido utilizados os mecanismos legais, já existentes, para promover uma maior uniformização dos julgados. Veja-se que, apesar de já existir, há muito tempo e em vários diplomas legais, ${ }^{5}$ procedimentos específicos, com vistas à uniformização de jurisprudência, estes são muito pouco valorizados.

Os próprios Tribunais não dão a devida atenção à dispersão de suas próprias decisões, sendo muito comum a existência de divergência entre julgados de turmas ou seções de um mesmo Tribunal. Esse é um problema grave, pois se os próprios Tribunais não possuem uma jurisprudência uniforme e coerente, os juízes de primeiro grau não têm uma orientação segura sobre a solução das diversas controvérsias e podem escolher, entre os posicionamentos divergentes, aquele que mais se coaduna com seu próprio entendimento.

Na medida em que os juízes insistem em sustentar posicionamentos jurídicos divergentes do entendimento dominante dos Tribunais, seja de segunda instância ou superiores, prejudica sobremaneira a celeridade na prestação jurisdicional, pois tal decisão certamente será reformada em eventual recurso, causando ônus desnecessário à parte.

É certo que deve haver mecanismos efetivos, sejam processuais ou extraprocessuais, para se provocar a alteração do entendimento dos Tribunais, desde que demonstradas razões fundadas, sejam de ordem jurídica, social, econômica ou outras.

De outro lado, decisões em consonância com as orientações firmes dos Tribunais desestimulam a interposição de eventuais recursos, que pouca ou nenhuma chance teriam de ser providos em segundo grau.

Não está a se defender aqui a vinculação obrigatória a todas as decisões judiciais anteriores ou precedentes. Uma vez, porém, que um Tribunal, seja superior ou mesmo de segunda instância, tenha firmado um determinado entendimento, ou seja, firmado a interpretação de um determinado dispositivo legal, não há razão jurídica nem lógica para que os órgãos judiciários submetidos a este específico Tribunal deixem de se orientar de acordo com aquele entendimento, exceto se afastado o precedente, seja por especificidade do caso (distinguishing), seja por restarem demonstradas fundadas razões para alteração de referido entendimento (overruling).

Defende-se, sim, uma mudança de cultura, uma nova postura dos Tribunais, no sentido de construir uma jurisprudência uniforme e coerente, que se revele uma fonte de orientação segura para todos os órgãos a ele submetidos e, de outro lado, uma atitude de maior humildade científica dos juízes, para que amoldem suas decisões aos precedentes e súmulas dos Tribunais. A irresignação com tais posicionamentos deve ser direcionada para críticas doutrinárias ou outros instrumentos capazes de provocar as devidas alterações, visando a decisões mais justas e afinadas com os valores fundamentais do ordenamento jurídico.

O pior consiste em que grande parte da doutrina tradicional do civil law, mesmo diante da grave divergência jurisprudencial e da multiplicidade de possibilidades hermenêuticas em torno de uma lei, tenta encobrir a necessidade de adoção de um instituto que garanta a segurança, a previsibilidade e a igualdade diante das decisões (ATAÍDE, 2013, p. 573).

\footnotetext{
5 Título IX, Capítulo I - Da uniformização da jurisprudência, Arts. 476 et seq., do CPC/73; Parte II, Título I, Capítulo IV, Seção I - Da uniformização da jurisprudência, Arts. 118 a 121, do Regimento Interno do STJ; Livro V, Título III, Capítulo III - Do Incidente de Uniformização de Jurisprudência, Arts. 446 et seq. do Regimento Interno do TJMG.
} 


\section{CONCLUSÃO}

Foram apontadas, de forma sucinta, as características dos sistemas jurídicos de tradição civil law e common law. Apesar de ainda manterem características bem próprias, é reconhecido que há um processo de aproximação entre eles, sendo certo que há uma maior produção e aplicação de leis no Direito anglo-saxônico e, ao mesmo tempo, uma maior valorização da jurisprudência e dos julgados no Direito romano-germânico.

O Brasil é um caso típico, em cujo ordenamento vem ocorrendo um processo contínuo de valorização da jurisprudência, com ampliação de hipóteses de vinculação obrigatória às decisões dos Tribunais Superiores, cujo exemplo maior é a nova regulamentação do tema, no CPC/2015.

Registre-se que este diploma legal, a rigor, não instituiu um sistema de precedentes vinculantes. $O$ que ele fez, na verdade, foi ampliar as hipóteses de decisões judiciais que têm força vinculante obrigatória para os demais órgãos do poder Judiciário. A expressão "precedente" no CPC/2015 tem significado próprio, diverso daquele utilizado no common law.

A vinculação aos precedentes é mecanismo utilizado nos sistemas de tradição common law há bastante tempo, porém não se trata de característica própria ou de mecanismo de uso exclusivo desse sistema.

Como se procurou demonstrar, tal mecanismo não é incompatível com o ordenamento jurídico brasileiro, de tradição civil law. Muito pelo contrário, o mecanismo de precedentes vinculantes, na medida em que possibilita uma uniformização e maior coerência das decisões judiciais, é exigência de qualquer ordenamento jurídico racional, em que a isonomia e a segurança jurídica sejam valores fundamentais.

Nesse sentido, a imposição de vinculação obrigatória a determinadas decisões judiciais, por meio de lei, talvez não seja mesmo a melhor forma de efetivação desse instrumento, tão necessário para promoção de uma maior uniformização, coerência e integridade da jurisprudência nacional. Essa, porém, parece ter sido a forma que o legislador encontrou para forçar uma mudança na prática e na cultura judiciária de juízes e Tribunais, no sentido de maior observância aos precedentes, em busca de maior isonomia e segurança jurídica.

\section{REFERÊNCIAS}

ABBOUD, Georges. Precedente judicial versus jurisprudência dotada de efeito vinculante. In: WAMBIER, Teresa Arruda Alvim (Org.). Direito jurisprudencial. São Paulo: RT, 2012.

ATAÍDE JR., Jaldemiro Rodrigues de. As tradições jurídicas de civil law e common law. In: DIDIER JR. et al. Novas tendências do Processo Civil. Salvador: Juspodium, 2013. p. 555-608.

ÁVILA, Humberto Bergman. Subsunção e concreção na aplicação do direito. In: MEDEIROS, Antônio Paulo Cachapuz. Faculdade de Direito da PUCRS: o ensino jurídico no limiar do novo milênio. Porto Alegre: Edipucrs, 1997. p. 413-465.

CAPPELLETTI, Mauro. Juízes legisladores? Tradução Carlos Alberto Álvaro de Oliveira. Porto Alegre: Sergio Antonio Fabres Editor, 1993.

. O controle de constitucionalidade das leis no Direito Comparado. 2. ed. Tradução Aroldo Plínio Gonçalves. Porto Alegre: Sérgio Antônio Fabris Editor, 1992.

DAVID, René. Os grandes sistemas do direito contemporâneo. Tradução Hermínio A. Carvalho. 4. ed. São Paulo: Martins Fontes, 2002.

LEITE, Gisele. Civil law versus Common law. Artigo. Conteúdo Jurídico, Brasília-DF: Fev. 2017. Disponível em: <http://conteudojuridico.com.br/?colunas\&colunista=2532_\&ver=2628>. Acesso em: 4 jan. 2018.

MANCUSO, Rodolfo de Camargo. Divergência jurisprudencial e súmula vinculante. 5. ed. São Paulo: Revista dos Tribunais, 2013. MARINONI, Luiz Guilherme. Precedentes obrigatórios. São Paulo: Revista dos Tribunais, 2010.

. Aproximação crítica entre as jurisdições de civil law e de common law e a necessidade de respeito aos precedentes no Brasil. Revista de Processo, São Paulo, ano 34, n. 172, p. 175-232, jun. 2009.

NOGUEIRA, Cláudia Albagli. O Novo Código de Processo Civil e o Sistema de Precedentes Judiciais pensando um paradigma discursivo da decisão judicial. Disponível em: <http://www.editoraforum.com.br/ef/index.php/noticias/o-novo-codigo-de-processo-civil-e-o-sistema-de-precedentes-judiciais-pensando-um-paradigma-discursivo-da-decisao-judicial-2> Acesso em: 29 dez. 2017.

OLIVEIRA, Rodrigo. Evolução histórica dos Precedentes Judiciais nos Sistemas de Common Law e Civil Law. Disponível em: <http://www.tex.pro.br/home/artigos/175-artigos-set-2013/4794-evolucao-historica-dos-precedentes-judiciais-nos-sistemas-de-common-law-e-civil-law-1>. Acesso em: 10 dez. 2017. 
PEDRON, Flávio Quinaud; OMMATI, José Emílio Medauar. Contribuição para uma compreensão ontológica dos Precedentes Judiciais. Revista Jurídica da Presidência, Brasília, v. 19, n. 119, p. 645-668, out. 2017/jan. 2018.

SABINO, Marco Antonio da Costa. O precedente judicial vinculante e sua força obrigatória no Brasil. Revista Dialética de Direito Processual, São Paulo, n. 85, p. 51-72, abr. 2010.

TALAMINI, Eduardo. O que são os precedentes vinculantes no CPC/15. Mar. 2016. Disponível em: <www.migalhas.com.br/dePeso/16,MI236392,31047-O+que+sao+os+precedentes+vincu lantes+no+ CPC15>. Acesso em: 12 dez. 2017.

TARUFFO, Michele. Precedente e giurisprudenza. In: Rivista Trimestrale Diritto e procedura civile, Milano: Giufrrè, a. 61, n. 3, 1996.

WAMBIER, Teresa Arruda Alvim. A uniformidade e a estabilidade da jurisprudência e o estado de direito - Civil law e common law. Revista Jurídica, Porto Alegre, v. 57, n. 384, p. 53-62, out. 2009.

ZANETI JR., Hermes. O valor vinculante dos precedentes. Salvador: JusPodivm, 2015. 